\title{
Influence of extraction conditions on the recovery lipids extracted from the dry biomass of duckweed Lemna minor
}

\author{
Yulia Smyatskaya ${ }^{1,{ }^{*}}$, Natalia Politaeva $^{1}$, Amira Toumi $^{1}$, and Lubov Olshanskaya ${ }^{2}$ \\ ${ }^{1}$ Peter the Great St. Petersburg Polytechnic University, 29 Politekhnicheskaya street, 195251, Saint \\ Petersburg, Russia. \\ ${ }^{2}$ Yuri Gagarin State Technical University of Saratov, 77 Politekhnicheskaya street, Saratov, \\ Saratovskaya oblast', 410054, Saratov, Russia
}

\begin{abstract}
Previous studies on the composition of lipid content of higher aquatic plants can be found in the literature. The present work aims to study the effect of various solvent extraction systems on the recovery of lipids extracted from the dry biomass of Lemna minor, using the same polar solvent (ethanol) and variating the non-polar solvent as follow: methanol-ethanol, chloroform-ethanol, hexane-ethanol, diethyl etherethanol, petroleum ether-ethanol at different volume ratio. The goal is to select a Sohxlet extraction method that shortens the extraction duration and increases the lipid recovery using various solvents. To intensify the extraction process, homogenization was used as a cell disruption method. It is shown that the yield of total lipids is increased by using homogenization from $4.6 \%$ to $6.0 \%$. When studying the influence of the solvent system, the highest yield of total lipids was obtained by using hexane-ethanol with a volume ration of 1:1 (8.0\% total lipids by dry mass). The yield of lipids recovered from dry biomass of Lemna minor increases by increasing the extraction time. The optimum extraction time was found to be no more than 300 minutes. The composition of the lipid fraction is mainly represented by sterols, fatty acids and triglycerides.
\end{abstract}

\section{Introduction}

Lipids (from the Greek lipos - "fat") are low-molecular-mass organic compounds, partially or completely insoluble in water. Lipids are of great interest as a potential source of biofuel. It is known that higher aquatic plants, microalgae, macroalgae and microorganisms contain valuable components, in particular, saturated and unsaturated fatty acids. The lipid composition of higher aquatic plants is presented in [1-4]. In the green algae of the lakes of Spain [5], styrenes, phosphoglyceride, phosphatidylethanolamine, and phosphatidylcholine were identified among the total lipids. In another study, the triglycerides structure of an algal biomass grown in California was established by nuclear magnetic resonance (NMR of H1-spectroscopy) [6]. Palmitic, margaric, palmitoleic, stearic, oleic and linoleic acids were

*Corresponding author: smyatskaya_yua@ @pbstu.ru 
identified by Gas chromatography (GC) in an algal biomass grown in Korea by [7]. In [8], saturated, mono- and polyene fatty acids (LC) with an even and odd number of carbon atoms of a linear and nonlinear structure (C14-C20) were determined by the GC in crustaceans of the White Sea. Saturated and unsaturated aliphatic aldehydes (C14-C30) were determined by the GC method [9] in selective ion monitoring mode in endemic sponges of Lake Baikal. The content of mounstaturated aldehydes (C22, C23, C24: 1) represented $94.2 \%$ and the diene-aldehyde $(\mathrm{C} 22, \mathrm{C} 24, \mathrm{C} 25: 2)$ represented $5.8 \%$ of the sum of the unsaturated aldehydes. In another study, the authors carried out a comparative analysis of the separation of neutral and polar lipids from wastes of fat and oil industry by solvents of different polarity, such as hexane, chloroform, butanol, diethyl ether and ethanol-chloroform mixture [10]. In [11], several solvents among which chloroform, acetone, mixtures of hexane-acetone, hexane-ethanol were used for lipid extraction from activated sludge. The hexane-ethanol mixture was found to be the best for lipid recovery. The extraction is most often carried out in Soxhlet apparatus [12] to increase the yield of lipid recovery, which allows the extraction time to be reduced to several hours using various solvents, depending on the target lipid components to be extracted.

Ultrasound is another method that allows to optimize the extraction process. The effect of ultrasound [15-17] provides the destruction of the cellular structure and the weakening of the bonding of lipids, proteins and carbohydrates to the solid matrix of the raw materials, which shortens considerably the extraction time as a result. It was established in [16] that the yield of lipids extracted by Soxhlet using hexane as a solvent for a 5 hour extraction time is quantitatively comparable to the yield of lipids obtained by ultrasonic bath in hexane for 30 minutes. The amount of lipids isolated by the Bligh and Dyer method (for 5 hours) is 6 times lower than when extracted with a mixture of methanol-chloroform in an ultrasonic bath for 30 minutes. The authors [18] carried out a comparative analysis of lipid extraction using various methods: infusion ( 8 hours), Soxhlet apparatus (4 hours), ultrasound and microwave radiation (30 minutes). Hexane was used as a solvent of extraction. The results showed that the extraction rate using Soxhlet apparatus was 2.5 times higher than the infusion method. Ultrasonic and microwave radiation increased by 2 to 4 times the yield of lipids in comparison with Soxhlet extraction. The closest to ultrasound exposure is the vibrational exposure. V. Ya. Mishchenko, S. F. Yatsun et al. [18$20]$ investigated the effects of vibration for the extraction of pectin substances from food products. AV Zhuchkov et al. [21] developed a high-intensity extractor for the enhancement of the extraction processes from biological raw material for the pharmacy industry. S. A . Kuznetsova et al. [22] found that the extraction with an addition of water and vibration treatment for 60 minutes increased the yield of extraction of arabinogalactan and dihydroquercitin by a factor of 2 . Yet, longer exposures lead to a decrease of the amount of recoverable compounds, which is apparently related to their destruction. Magnetic treatment is technique applied in the field of extraction. In the work of T.V. Moskalenko et al. [23], a comparative analysis of the yield of humic acids extracted from peat was carried out with and without magnetic and ultrasonic exposure.

Carbon dioxide (CO2) is widely used as an environmentally friendly lipid extraction solvent [23]. The solubility and selectivity of supercritical carbon dioxide depends on the variation of the extraction parameters such as temperature, pressure, and flow rate of $\mathrm{CO} 2$ (supercritical point $7.4 \mathrm{MPa}$ and $31.1^{\circ} \mathrm{C}$ ). The yield of lipids obtained by supercritical CO2 extraction is quantitatively comparable to the one reached by Soxhlet extraction [2].

The purpose of the present work is to select the optimal conditions for the extraction of lipids e from the higher aquatic plant Lemna minor. 


\section{Materials and methods}

The object of the study was the high aquatic plant Lemna minor.

This duckweed was grown under natural conditions in the Leningrad Region. After being harvested, it was washed with tap water previously disinfected with the use of a Membrane Electrolysis. The washed duckweed flakes were subjected to a temperature shock of $-20^{\circ} \mathrm{C}$. Later, the duckweed were thawed and dried to constant weight under an infrared lamp first and later, in the air-drying equipment unit "Sukhovei".

The mechanic disintegration of the duckweed was carried out in a homogenizer of the brand $\mathrm{Tu} 302$ (Poland) at different homogenization rates, $\mathrm{V}=10000 \mathrm{rpm}$. For the homogenization process, $5 \mathrm{~g}$ of dried duckweed was poured into $10 \mathrm{ml}$ of ethanol. The mixture was homogenized for 3 minutes. The lipid extraction was carried out in the Sohxlet apparatus Büchi E-812 SOX model. For the extraction process, $1 \mathrm{~g}$ of each sample (dried duckweed biomass with or without the action of mechanical disintegration) was used and placed in a cellulose thimble (dimensions $35 \mathrm{~mm} \times 78 \mathrm{~mm}$ ). The extracts were completely dried in a SNOL oven at $45^{\circ} \mathrm{C}$ and weighed on an analytical scale (OHAUS RV 214). The percentage yield of the extracted lipids was determined by the formula (1).

$$
M=\left(m_{1}-m_{0}\right) \times 100 / m
$$

M: Percentage of extracted lipids by mass (\%),

$\mathrm{m}$ : Mass of dry biomass sample (g),

$\mathrm{m} 1$ : Mass of the beaker after extraction $(\mathrm{g})$;

$\mathrm{m} 0$ : Mass of the beaker prior to extraction $(\mathrm{g})$.

For the same of the experiment, three parallel essays were performed and the average lipid yields were calculated.

Qualitative analysis of the lipid composition was carried out by thin layer chromatography (TLC) using a Sorbfil densitometer with software. For this analysis, $3 \mu \mathrm{l}$ of extract samples were applied to a chromatographic plate of PTSX-AF-B grade. The plate was placed in a chromatographic chamber prefilled by a mixture of solvents: petroleum ether-diethyl ether-acetic acid in a ratio of 90: 10: 1. The plate was immersed in the solvent mixture at a 5-6 mm height. The elution continued for 50-60 minutes at room temperature. The plate was then dried and sprayed with a $30 \%$ solution of sulfuric acid. The sprayed plates were kept in a drying cabinet heated to a temperature of $180^{\circ} \mathrm{C}$ for 30 minutes. As a result, all lipids charred and formed black spots. Afterwards, the values of the retention factors (Rf) of each substances were calculated.

\section{Results and Discussion}

In the first stage, the extraction solvents used was a mixture of hexane and ethanol in a volume ratio of 9: 1 . For $100 \mathrm{~g}$ of biomass, $100 \mathrm{ml}$ of extraction solution was required. It was determined that, to complete the extraction of lipids from dry biomass Lemna minor duckweed, it is necessary to perform 15 extraction cycles, then a 5-minute rinsing step and a 30-minute drying step. The yield of the lipids extracted from the biomass of Lemna minor duckweed reached $4.6 \%$ for the samples of dry biomass without disintegration and $6.0 \%$ for the homogenized biomass samples.

The next stage of the work was to select of the optimal nonpolar solvent (hexane, petroleum ether, chloroform, diethyl ether), used combined with ethanol as the polar solvent. The yield of the total lipids is shown in Table 1.

Table 1. Influence of a non-polar solvent on the yield of lipids extracted from the dry biomass Lemna minor 


\begin{tabular}{|l|c|c|c|c|}
\hline \multicolumn{1}{|c|}{ Solvent } & $\begin{array}{c}\text { Solvent } \\
\text { volume } \\
\text { ratio }\end{array}$ & $\begin{array}{c}\text { Lipid } \\
\text { yield, } \\
\%\end{array}$ & $\begin{array}{c}\text { Acute Oral } \\
\text { Toxicity of the } \\
\text { non-polar } \\
\text { solvent on rats } \\
\text { (LD }\end{array}$ & $\begin{array}{c}\text { Acute } \\
\text { mg } / \mathrm{kg}\end{array}$ \\
$\begin{array}{c}\text { inhalation } \\
\text { toxicity of } \\
\text { the non- } \\
\text { polar on rats } \\
\text { LC }_{50}, \mathrm{mg} / 1\end{array}$ \\
\hline Hexane- ethanol & $90: 10$ & $6,0 \pm 0,5$ & 16,0 & $259,3 / 4 \mathrm{~h}$ \\
\hline $\begin{array}{l}\text { Petroleum ether- } \\
\text { ethanol }\end{array}$ & $90: 10$ & $4,8 \pm 0,5$ & $>2,0$ & $54,0 / 4 \mathrm{~h}$ \\
\hline $\begin{array}{l}\text { Chloroform- } \\
\text { ethanol }\end{array}$ & $90: 10$ & $5,5 \pm 0,5$ & 695 & - \\
\hline $\begin{array}{l}\text { Diethyl ether- } \\
\text { ethanol }\end{array}$ & $90: 10$ & $2,2 \pm 0,5$ & 260 & \\
\hline
\end{tabular}

The highest lipid yield was achieved using hexane-ethanol solvent system $(6.0 \%)$ and chloroform-ethanol (5.5\%). If the choice of the extraction solvent takes into consideration not only its efficiency, but also its toxicity, then hexane is the most effective and the safest solvent (regarding its $\mathrm{LC}_{50}$ ).

Next, the effects of the ratio polar to nonpolar solvents (hexane-ethanol) (Table 2) and the extraction time (Table 3) on the yield of lipids extracted from dry biomass of Lemna minor duckweed were investigated.

Table 2. Influence of the volume ratio of polar to nonpolar solvents on the yield of lipids extracted from the dry biomass Lemna minor

\begin{tabular}{|c|c|c|}
\hline Solvents & Solvents volume ratio & Lipid yield, \% \\
\hline \multirow{3}{*}{ Hexane-ethanol } & $90: 10$ & $6,0 \pm 0,5$ \\
\cline { 2 - 3 } & $50: 50$ & $8,0 \pm 0,5$ \\
\cline { 2 - 3 } & $10: 90$ & 0,0 \\
\hline
\end{tabular}

Table 3. Effect of extraction time on yield of lipids extracted from the dry biomass Lemna minor

\begin{tabular}{|l|c|c|c|}
\hline \multicolumn{1}{|c|}{ Solvents } & $\begin{array}{c}\text { Number of } \\
\text { cycles }\end{array}$ & $\begin{array}{c}\text { Extraction time, } \\
\text { min }\end{array}$ & $\begin{array}{c}\text { Lipid yield, } \\
\%\end{array}$ \\
\hline \multirow{4}{*}{$\begin{array}{l}\text { Hexane- ethanol } \\
\text { (9:1) }\end{array}$} & 5 & 43 & $4,7 \pm 0,5$ \\
\cline { 2 - 4 } & 10 & 86 & $5,5 \pm 0,5$ \\
\cline { 2 - 4 } & 15 & 128 & $6,0 \pm 0,5$ \\
\cline { 2 - 4 } & 20 & 171 & $7,1 \pm 0,5$ \\
\cline { 2 - 4 } & 25 & 214 & $7,9 \pm 0,5$ \\
\cline { 2 - 4 } & 35 & 300 & $8,0 \pm 0,5$ \\
\hline
\end{tabular}

It can be seen from Table 2 that the maximum yield of lipids is reached when using solvents in the ratio 50:50 for extraction. When studying the effect of extraction time, it was shown that the yield of lipids from the dry biomass of Lemna minor duckweed increases with increasing extraction time (Table 3). It is not advisable to perform extraction of more than 300 minutes ( 35 cycles), during this period all lipids pass into the extract.

In the obtained lipid fraction from dry biomass Lemna minor duckwas using thin-layer chromatography, the lipid classes were determined by the relative chromatographic mobility of substance-R (Fig. 1). 


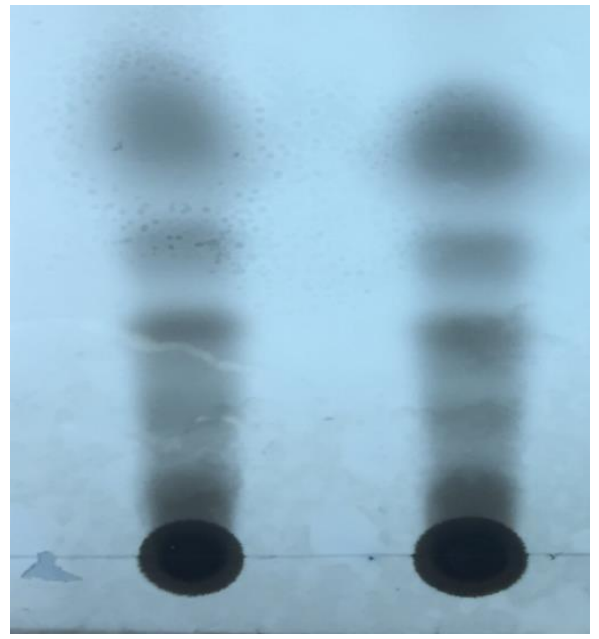

Fig. 1. Separation of lipids obtained from duckweed Lemna minor by thin layer chromatography

According to the reference data, the following lipid classes were identified: sterols, fatty acids and triglycerides.

\section{Conclusions}

As a result of this study, it was shown that the yield of the total lipids extracted from the dry biomass of duckweed - Lemna minor increases with the use of homogenization from $4.6 \%$ to $6.0 \%$.

It was experimentally proved that the maximum yield of total lipids was obtained using a hexane-ethanol solvent system $(6.0 \%)$.

It was found that the maximum yield of lipids was reached when extracting using a mixture of hexane - ethanol at a 50:50 ratio. The effectiveness of the lipid extraction from the dry biomass of Lemna minor increased with the prolongation of extraction time untill it reached a plateau. The optimum Sohxlet extraction time was found to be no more than 300 minutes.

The composition of the obtained lipid fractions was mainly represented by sterols, fatty acids and triglycerides.

The research was carried out within the framework of the implementation of the federal target program "Research and development in priority areas for the development of the scientific and technological complex of Russia for 2014-2020" with the project theme: "Development and implementation of innovative biotechnologies for the processing of microalgae Chlorella sorokiniana and Lemna minor duckweed" (AGREEMENT No. 14.587 .21.0038, July 17, 2017). Unique identifier of the project: RFMEFI58717X0038.

\section{References}

1. K.A. Kirichenko et al., Chemistry of plant raw material 97, 2 (2011)

2. P. C. K. Cheung et.al., J. Agric., Food Chem. 46, 4228 (1998)

3. R. A. Holser, D. E. Akin, Ind Crops Prod. 27, 236-240 (2008)

4. L. N. Ol'shanskaya, N. A. Politaeva, O. A. Aref'eva, R. S. Valiev, Nature Environment and Pollution Technology 17, 619-624 (2018).

5. F. J. L. Gordillo et.al., J, Appl Phycol. 10, 135 - 144 (1998) 
6. G. Young, F. Nippgen et.al., Sep. Purif. Technol. 72, 118-121 (2010)

7. J.Y. Lee et.al., Bioresour. Technol. 101, 575 (2010)

8. P. Tkach, R. W. Vysotskaya, V.F. Bryazgin, Contemporary Problems of Science and Education 5, 18 (2007)

9. A. B. Imbs, A. L. Vereshchagin, Bioorganic Chemistry 6, 651-659 (2005)

10. A. S. Sikorskaya, A.A. Nazarova, V.F. Selemenev, Sorption and chromatographic processes 8 (2) , 350-354 (2008)

11. O.V. Kolesova, G.V. Leontieva, V.V. Volkhin, Herald of the PNIPU. Chemical technology and biotechnology 12, 165 (2011)

12. L.M. Fedoseeva, T.A. Kharlampovich, Chemistry of plant raw materials 4, 213-217 (2011)

13. E.T. Yamansarova et al., Vestn. Bashkir. un-ta. 13, 18 (1) (2008)

14. P. Manirakiza et al., J Food Compost Anal. 14, 93 (2001)

15. B. Raj, V. Rajendran, P. Palanichamy, Science and Technology of Ultrasonics, 576 (2006)

16. V. I. Martovschuk et.al., New Technologies 1, 17 (2011)

17. K. Vilkhu et.al., Innov. Food Sci. Emerg. Technol. 9, 161-169 (2008)

18. G. Cravotto et al., Ultrason. Sonochem. 15, 898-902 (2008)

19. V. Ya. Mishchenko, EV Mishchenko, Izv. Samar. sci. Center of the Russian Academy of Sciences 11, 5 (2) (2009)

20. S.F. Yatsun, V. Ya. Mishchenko, EV Mishchenko, Izv. supreme. training. institutions. North-Caucasian region. Series: Engineering Sciences 5, 99 (2008)

21. A.V. Zhuchkov, A.A. Andreev, IV International Conference "Extraction of Organic Compounds" (EOS-2010), Voronezh 257 (2010)

22. S.A. Kuznetsova et al., Chemistry for Sustainable Development 13, 261-269 (2005)

23. T.V. Moskalenko, V.A. Mikheev, O.S. Danilov, Mining Information and Analytical Bulletin 10, 95 (2011)

24. A. P. Sanchez-Camargo et al., J Supercrit Fluids. 56, 164-173 (2011) 